[Chem. Pharm. Bull.

35( 6 )2504-2509(1987)

\title{
Release Characteristics of Nifedipine Sustained-Release Granules in Vitro and in Healthy Subjects
}

\author{
NAONORI KOHRI,${ }^{a}$ KATSUMI MiYAZAKI,${ }^{a}$ TAKAICHI ARITA, ${ }^{*, a}$ \\ Hisashi Shimono, ${ }^{b}$ AKIKAZU NomUra ${ }^{b}$ \\ and HISAKAZU YASUDA ${ }^{b}$ \\ Department of Pharmacy $y^{a}$ and Department of Cardiovascular Medicine, ${ }^{b}$ \\ Hokkaido University Hospital, School of Medicine, \\ Hokkaido University, Sapporo 060, Japan
}

(Received October 27, 1986)

\begin{abstract}
The release characteristics of nifedipine sustained-release granules, composed of ethylcellulose, hydroxypropylmethylcellulose and corn starch, were examined in vitro as well as in healthy subjects. The release of nifedipine from the granules in vitro was not first-order, but a linear relationship up to about $40 \%$ release was obtained based on the Higuchi equation. The release rate was not strongly influenced by $\mathrm{pH}$, stirring speed, surfactant or ionic strength. These granules were administered to healthy subjects and the plasma levels of nifedipine were compared with those after administration of nifedipine soft gelatin capsule. Plasma levels following the administration of the granules were prolonged as compared with those in the case of the soft gelatin capsule, and plasma levels of about $13 \mathrm{ng} / \mathrm{ml}$ at $12 \mathrm{~h}$ post-dosing were detected. The known problem of marked inter-subject variability of the plasma levels was not encountered after administration of the sustained-release granules, presumably due to the multiple-units dosage form and the established low sensitivity of the drug release rate to the in vitro environment, i.e., $\mathrm{pH}$, stirring speed, surfactant and ionic strength.
\end{abstract}

Keywords-nifedipine; sustained-release granules; release characteristics; oral administration; healthy subject; plasma level; inter-subject variability

\section{Introduction}

The intensity of the pharmacologic or toxic effect of a drug is considered to be related to the concentration of the drug at the receptor sites, which are usually located in the tissue cells. In practice, the plasma drug level is generally employed for monitoring the course of therapy, since most of the tissue cells are richly perfused with tissue fluids or plasma. The drug concentration is determined by the rates of absorption, distribution and clearance. The effect of a drug may be controlled by reducing its rate of absorption, by delaying the rate at which it is inactivated, or by retarding its excretion. ${ }^{1}{ }^{1}$ One method to prolong the plasma drug level is to employ a sustained-release formulation. ${ }^{2}$

In preparing sustained-release products, it is desirable to avoid the use of special apparatus such as a coating pan or a fluidized bed coating machine, and techniques such as microencapsulation, on grounds of convenience and expence. In the present study we chose nifedipine as a model compound. The extent of bioavailability of nifedipine is low when the drug is administered orally in a crystalline form because of poor water-solubility. ${ }^{3)}$ Several water-soluble formulations have been developed, ${ }^{4)}$ but the elimination half-life of nifedipine after administration of these formulations is only $3.43 \mathrm{~h}^{4 b)}$ It is, therefore, necessary to prolong the plasma levels in order to maintain the clinical effect. Recently some sustainedrelease formulations have been developed. ${ }^{5)}$ We also previously formulated two kinds of sustained-release granules; one with $\mathrm{pH}$-dependent release and the other with $\mathrm{pH}$-independent 
release. ${ }^{6)}$ The $\mathrm{pH}$-independent release granules were superior to the $\mathrm{pH}$-dependent release granules with respect to prolonging the effective plasma levels and minimizing the intersubject variability when administered to rabbits. ${ }^{6}$ )

In the present study the effects of stirring speed, surfactant and ionic strength $(\mu)$ on the release rate of nifedipine from the $\mathrm{pH}$-independent release granules were examined in vitro to investigate the release characteristics. Furthermore, the $\mathrm{pH}$-independent release granules were administered to healthy subjects and the plasma levels after administration of the granules were compared with those after nifedipine soft gelatin capsule.

\section{Experimental}

Materials - Ethylcellulose (100 cps, Wako Pure Chemical Industry, Osaka, Japan), hydroxypropylmethylcellulose (HPMC; $50 \mathrm{cps}$, Sigma Chemical Co., St. Louis, Mo. U.S.A.), corn starch (Hoei Yakuko, Osaka, Japan), nifedipine soft gelatin capsule (Adalat, Bayer) were used. Crystalline nifedipine (lot I34A, Kanebo Ltd., Osaka, Japan) was a gift. All other chemicals were of reagent grade.

Methods - All experiments were carried out in a dark room, because of the high sensitivity of nifedipine to light. ${ }^{7)}$

Preparation of Granules - One gram of nifedipine, $3 \mathrm{~g}$ of ethylcellulose and $3 \mathrm{~g}$ of HPMC were dissolved in ethanol-dichloromethane $(1: 1, \mathrm{v} / \mathrm{v})$ and then $8 \mathrm{~g}$ of corn starch was added with agitation by a magnetic stirring bar in a jacketed beaker connected to a thermostated water bath (Iuchi, Racom-Ace HT-01C). A slurry with suitable toughness was obtained by evaporating the solvent while maintaining the water bath at $70^{\circ} \mathrm{C}$, and then the product was forced through a 35 -mesh sieve. The resultant cylindrically shaped initial materials clung to the sieve surface even after passing through the pores. After drying the initially formed materials at $50^{\circ} \mathrm{C}$, the sieve was scraped with a spatula. A fraction of granules with a size of between 32-mesh and 35-mesh was obtained, in this way.

Release Studies - The JPX paddle method ${ }^{8)}$ was employed for investigating the release rates from the granules. A cylindrical releasing vessel in a constant temperature water bath was used. The paddle was located at a depth of $25 \pm 2 \mathrm{~mm}$ from the bottom. The granules $(75 \mathrm{mg})$ were dispersed in $500 \mathrm{ml}$ of various kinds of medium: distilled water; distilled water containing 0.1 or $1 \%(\mathrm{w} / \mathrm{v})$ polysorbate $80 ; 0.1 \mathrm{~N} \mathrm{HCl}(\mathrm{pH} 1.2, \mu=0.100 \mathrm{M}) ; 0.1 \mathrm{~N} \mathrm{HCl}$ containing $1 \%$ sodium chloride $(\mathrm{pH}=1.1, \mu=0.272 \mathrm{M}) ; 0.05 \mathrm{M}$ phosphate buffer $(\mathrm{pH}=7.0, \mu=0.110 \mathrm{M}) ; 0.1 \mathrm{M}$ phosphate buffer $(\mathrm{pH}=7.0, \mu=0.222 \mathrm{M})$, at $37 \pm 0.5^{\circ} \mathrm{C}$. The paddle was rotated at $150 \mathrm{rpm}$. In addition, rotation rates of 50 and $250 \mathrm{rpm}$ were also used to examine the effect of stirring rate on the release rate. Samples $(5 \mathrm{ml})$ were removed at suitable intervals and filtered through membrane filters with a pore size of $0.45 \mu \mathrm{m}$ (Toyo Roshi Co., Ltd.). The solutions were analyzed spectrophotometrically against a blank at $238 \mathrm{~nm}$. Fresh medium $(5 \mathrm{ml})$ was added to the dissolution vessel immediately after each sample was removed to maintain the original volume. Triplicate runs were made in each study.

Solubility Studies- Saturated solutions of nifedipine were prepared in each dissolution medium and equilibrated at $37 \pm 0.5^{\circ} \mathrm{C}$ in a thermostated water bath for $24 \mathrm{~h}$. Each sample was filtered through the same type of membrane as used in the release studies. After suitable dilution with the same medium, these samples were spectrophotometrically analyzed against a blank at 238 or $340 \mathrm{~nm}$. Triplicate runs were made in each study.

Content of Drug in Granules - The granules $(30 \mathrm{mg})$ were dissolved in $20 \mathrm{ml}$ of ethanol-dichloromethane (1:1, $\mathrm{v} / \mathrm{v}$ ) by shaking for $30 \mathrm{~min}$ and then centrifuged at $1500 \mathrm{~g}$ for $5 \mathrm{~min}$. The supernatant was appropriately diluted with ethanol-dichloromethane $(1: 1, \mathrm{v} / \mathrm{v})$ and spectrophotometrically analyzed against a blank at $340 \mathrm{~nm}$. Triplicate runs were made in each study.

Administration of Drug - Four healthy male subjects (age range $21-32$ years) participated in the present study. The study was designed in a randomized crossover fashion with at least a 14-d interval between doses. Each subject received orally $10 \mathrm{mg}$ of nifedipine in a soft gelatin capsule or $20 \mathrm{mg}$ of nifedipine in sustained-release granules with $100 \mathrm{ml}$ of tap water at 9:00 a.m. after overnight fasting. About $5 \mathrm{ml}$ of blood was obtained immediately before drug administration (time 0 ) and at $0.25,0.5,0.75,1,1.5,2,3,4,6,9$ and $12 \mathrm{~h}$ post-dosing. A cannula was inserted into a forearm vein and this was used for blood withdrawal for the first $4 \mathrm{~h}$. After that, blood was collected from a forearm vein by means of a syringe. The blood specimens were centrifuged and the separated plasma samples were stored at $-20^{\circ} \mathrm{C}$ with protection from light until assay was done. The subjects remained supine for the first $2 \mathrm{~h}$. Beverage was permitted during the study except in the first $4 \mathrm{~h}$. The subjects were only allowed to take food at 4 and $10 \mathrm{~h}$ post-dosing.

Assay of Nifedipine in Plasma - Nifedipine in all samples was assayed according to the high performance liquid chromatography (HPLC) method of Miyazaki et al. ${ }^{9)}$ In this study, $1 \mathrm{ml}$ of plasma was used. Methanol (100 $\mu$ l) and acetonitrile $(3 \mathrm{ml})$ were added to $1 \mathrm{ml}$ of plasma in a brown test tube, and agitated with a vortex mixer. After centrifugation at $1500 \mathrm{~g}$ for $5 \mathrm{~min}, 3 \mathrm{ml}$ of the supernatant was transferred into a brown test tube containing $1 \mathrm{ml}$ of distilled water, and then $4.5 \mathrm{ml}$ of acetone-chloroform mixture $(1: 1, \mathrm{v} / \mathrm{v})$ was added. The mixture was shaken for 
$10 \mathrm{~min}$ and then centrifuged at $1500 \mathrm{~g}$ for $5 \mathrm{~min}$. The aqueous layer was aspirated off, and $5 \mathrm{ml}$ of the organic layer was transferred into a brown test tube, and evaporated to dryness in a centrifugal evaporator (Model RD-21, Yamato Scientific, Tokyo, Japan) at $45^{\circ} \mathrm{C}$ for $30 \mathrm{~min}$. The residue was dissolved in $100 \mu \mathrm{l}$ of the mobile phase containing butamben as an internal standard $(2 \mu \mathrm{g} / \mathrm{ml})$, and $20 \mu \mathrm{l}$ of the solution was injected into the HPLC system. The chromatographic conditions were the same as previously reported. ${ }^{9)}$ The wavelength for the assay of nifedipine was $238 \mathrm{~nm}$ at 0.0025 AUFS.

Statistical Analysis_-Equality of variances and the significance differences in the peak plasma levels $\left(C_{\max }\right)$, the times to the peak plasma levels $\left(t_{\mathrm{max}}\right)$ and areas under the concentration-time curves $\left(A U C_{0-12 \mathrm{~h}}\right)$ between capsule and granules were tested by means of the $\mathrm{F}$ and $t$ tests, respectively.

\section{Results and Discussion}

We previously reported that the release rate of nifedipine from the $\mathrm{pH}$-independent release granules could be controlled by altering the polymer ratio of HPMC-ethylcellulose used as a binder, and also that the release curves were not influenced by the $\mathrm{pH}$ of the dissolution medium. ${ }^{6}$ The mechanism of drug release from the granules presumably involves the formation of a hydrated zone of HPMC on the surface of the granular matrix. ${ }^{10,11)}$ This would be the first step in the formation of a transport channel. Part of the drug would be diffused through the hydrated zone and be released into the medium while the remainder would be liberated when the hydrated zone dissolved. Altering the HPMC-ethylcellulose ratio in the polymer composite mixture would affect the release rate markedly. ${ }^{10)}$ When there is a low content of HPMC in the granular matrix, a comparatively slow release rate might be expected, due to the support provided by the hydrophobic ethylcellulose. In the present study, further investigations of the release characteristics from this sustained-release granular matrix were carried out. The content of nifedipine in the granules was $95.9 \pm 3.70 \%$ (mean \pm S.D.; $n=7)$.

Wagner ${ }^{12)}$ showed that most sustained-action dosage forms for which release-time data are available in the literature released their contained drug into fluids in the in vitro test at pseudo- (or apparent-) first-order rates. It has become rather common practice to plot data derived from dissolution rate studies on conventional tablets and capsules in conformity with first-order kinetics. The percent drug remaining in the granules is plotted on the logarithmic scale of semilogarithmic graph paper against time in hours on the abscissa. The lack of linearity over the entire range in our case indicates that the process is not first-order. Therefore, an attempt was made to determine whether the drug release could be described by a diffusion equation proposed by Higuchi. ${ }^{13)}$ The plot gave a linear relationship up to about $40 \%$ release. The remainder is released more slowly, presumably due to greater occlusion of the drug by the insoluble ethylcellulose matrix ${ }^{14)}$ or failure to maintain the sink condition.

We also considered the effects of factors such as stirring speed, wetting and ionic strength on the release rate in vitro. The release rate was not much influenced even when the stirring speed was increased from 50 to $250 \mathrm{rpm}$. This indicates that the diffusion in the stationary layer at the outer wall of the granules was not rate-limiting. Furthermore, the effect of polysorbate 80 as a surfactant on the release rate was examined at $150 \mathrm{rpm}$. The solubilities of nifedipine at $37{ }^{\circ} \mathrm{C}$ in distilled water containing $0 \%, 0.1 \%$ and $1 \%(\mathrm{w} / \mathrm{v})$ polysorbate 80 were found to be $11.0,26.6$ and $172.7 \mu \mathrm{g} / \mathrm{ml}$, respectively (Table I). However, the release rates were less influenced by addition of polysorbate 80 . It is interesting that solubilization and wetting by polysorbate 80 had little effect on the release rate despite the poor water-solubility of nifedipine. Since wetting depends markedly on surface tension, whereas the release rates were not correlated with surface tension, wetting was not a rate-limiting step for these processes. Similar results have been reported by Weintraub and Gibaldi, ${ }^{15)}$ and Schott et al. ${ }^{16)}$

We also examined the effect of ionic strength on the release rate at $150 \mathrm{rpm}$. The solubility of nifedipine was decreased by about $15 \%$ with increment of the ionic strength from 
TABlE I. Solubilities of Nifedipine in Various Media at $37^{\circ} \mathrm{C}$

\begin{tabular}{lr}
\hline \hline \multicolumn{1}{c}{ Dissolution medium } & Solubility $(\mu \mathrm{g} / \mathrm{ml})$ \\
\hline Distilled water & $11.0 \pm 0.38$ \\
Distilled water containing $0.1 \%(\mathrm{w} / \mathrm{v})$ polysorbate 80 & $26.6 \pm 0.83$ \\
Distilled water containing $1 \%(\mathrm{w} / \mathrm{v})$ polysorbate 80 & $172.7 \pm 2.02$ \\
$0.1 \mathrm{~N} \mathrm{HCl}(\mu=0.100 \mathrm{M})$ & $11.0 \pm 0.46$ \\
$0.1 \mathrm{~N} \mathrm{HCl}$ containing $1 \% \mathrm{NaCl}(\mu=0.272 \mathrm{M})$ & $9.4 \pm 0.40$ \\
$0.05 \mathrm{M}$ phosphate buffer, $\mathrm{pH} 7(\mu=0.110 \mathrm{M})$ & $9.4 \pm 0.12$ \\
$0.1 \mathrm{~m}$ phosphate buffer, $\mathrm{pH} 7(\mu=0.222 \mathrm{M})$ & $8.5 \pm 0.12$ \\
\hline
\end{tabular}

Each result is a mean value \pm S.D. $(n=3)$.

TABle II. Pharmacokinetic Parameters of Nifedipine after Administration of Soft Gelatin Capsule and Sustained-Release Granules

\begin{tabular}{ccccc}
\hline \hline Parameter & Capsule & Granules & $t$ test & F ,test \\
\hline$C_{\max }$ & $240.8^{a)} \pm 44.32$ & $55.9 \pm 3.13$ & - $^{b)}$ & U.E.V. ${ }^{d)}$ \\
$(\mathrm{ng} / \mathrm{ml})$ & $(148.8-332.2)$ & $(47.9-62.9)$ & & \\
$t_{\max }$ & $0.9^{a} \pm 0.36$ & $2.4 \pm 0.55$ & $\mathrm{NS}^{c}$ & E.V. $^{e}$ \\
$(\mathrm{~h})$ & $(0.5-2.0)$ & $(1.5-4.0)$ & & \\
$A U C_{0-12 \mathrm{~h}}$ & $454.3^{a)} \pm 92.61$ & $340.6 \pm 20.15$ & $\mathrm{NS}^{c)}$ & U.E.V. ${ }^{d)}$ \\
$(\mathrm{ng} \cdot \mathrm{h} / \mathrm{ml})$ & $(246.8-664.0)$ & $(287.5-372.1)$ & & \\
\hline
\end{tabular}

Each result is a mean value \pm S.E.M. $(n=4)$. a) Corrected for the dose by multiplying by 2 . b) Significant at $p<0.05$. c) Not significant at $p>0.05$. d) U.E.V., unequal variances at $p<0.05$. $e$ ) E.V., equal variances at $p>0.05$.

0.100 to $0.272 \mathrm{M}$ in $0.1 \mathrm{~N} \mathrm{HCl}$ (Table I). In addition, the solubility of nifedipine was decreased by about $10 \%$ with increment of the ionic strength from 0.110 to $0.222 \mathrm{M}$ in the phosphate buffer ( $\mathrm{pH}$ 7) (Table I). The release rates, however, were less influenced by these differences in ionic strength. Similar results were reported by Baggesen and Bechgaard ${ }^{17)}$ : the release rates of propoxyphene hydrochloride from pellets were not much influenced by ionic strength between 0.097 and $0.133 \mathrm{M}$. These results indicate that the $\mathrm{pH}$-independent release granules prepared in the present study might be relatively impervious to factors such as $\mathrm{pH}$, peristaltic movement, bile, or ionic strength of the GI fluid in the alimentary tract.

The mean plasma nifedipine levels of the sustained-release granules were higher over the $2-12 \mathrm{~h}$ period than those in the case of the soft gelatin capsule. The pharmacokinetic parameters for the two formulations are not directly comparable since the dose of nifedipine administered as granules was double the dose in the capsule. However, dose proportionality studies of nifedipine established linear kinetics. ${ }^{5 a, 6,18)}$ Thus, after correcting for the dose by multiplying $C_{\max }$ and $A U C_{0-12 \mathrm{~h}}$ by 2 for the capsule, these parameters were analyzed statistically (Table II). The peak plasma level for the granules was significantly lower $(p<0.05)$ than that for the capsule (Table II). The extent of bioavailability of the granules was about $75 \%$ of the capsule, which was similar to that found in rabbits previously. The $t_{\max }$ value for the granules was larger than that for the capsule (Fig. 2), but there was no statistically significant difference (at $p>0.05$ ) in $A U C_{0-12 \mathrm{~h}}$ or $t_{\max }$ values between the two formulations. When the pharmacokinetic parameters were compared for the two formulations for unequal variances, the $C_{\max }$ and $A U C_{0-12 \mathrm{~h}}$ values after administration for the granules were significantly smaller $(p<0.05)$ than those of the capsule (Table II). This smaller inter-subject variability may be attributed to the following factors. (1) The granular formulation which is a type of multiple-units dosage form ${ }^{19)}$ would be dispersed quickly in the 


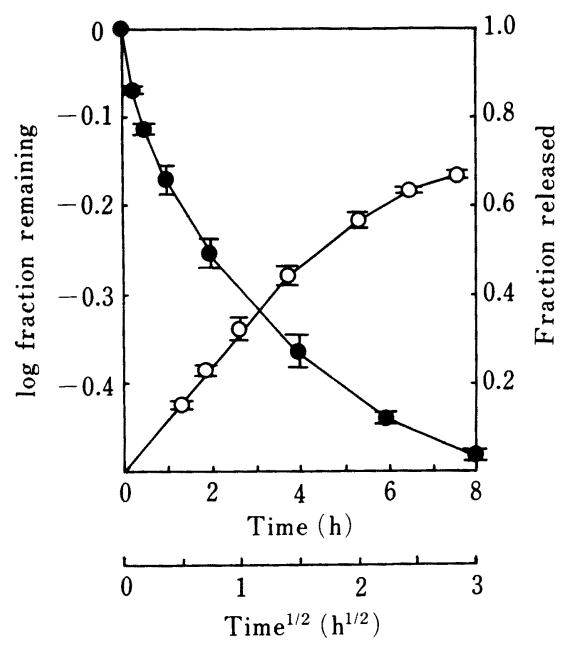

Fig. 1. Comparison between log Remaining Fraction-Time Plot and Fraction ReleasedSquare Root of Time Plot of Data from Nifedipine Sustained-Release Granules

$(\bullet), \log$ fraction remaining versus time; $(\bigcirc)$, fraction released versus square root of time. Each point represents a mean value \pm S.D. $(n=3)$.

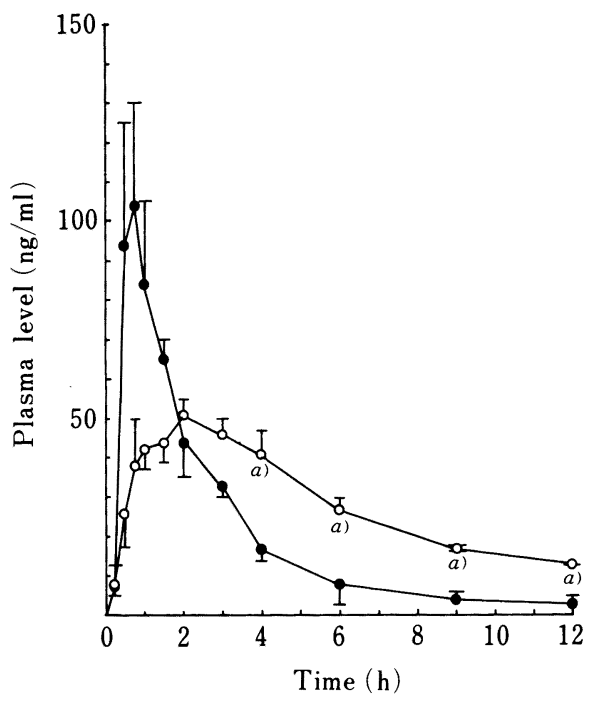

Fig. 2. Mean Plasma Nifedipine Profiles after Oral Administration of Two Formulations

(O), soft gelatin capsule containing $10 \mathrm{mg}$ of nifedipine; $(O)$, sustained release granules containing $20 \mathrm{mg}$ of nifedipine. Each point represents a mean value \pm S.E.M. $(n=4)$. a) $p<0.05$.

stomach and scattered through the small intestine, where they would be distributed widely. ${ }^{20)}$ Thus, inter-subject variability caused by differences in the transit time are minimized with such formulations. (2) The sustained-release granules prepared in the present study would be less influenced by factors such as $\mathrm{pH}$ and ionic strength in the GI fluid, peristaltic movement, or bile, based on the results obtained from the release studies in vitro.

The hypotensive effect of nifedipine in hypertensive patients was related to the plasma level $^{21)}$ and the minimum nifedipine level required for the effect was $10-15 \mathrm{ng} / \mathrm{ml} .^{5 b, c, 22)}$ Thus the patients should receive capsules every $6 \mathrm{~h}$ (total: $40 \mathrm{mg} / \mathrm{d}$ ) based on the results shown in Fig. 5. However, the granular formulation would be expected to be effective even if the patients receive it every $12 \mathrm{~h}$ (total: $40 \mathrm{mg} / \mathrm{d}$ ). The plasma levels at $4,6,9$ and $12 \mathrm{~h}$ after administration of the granules were significantly higher $(p<0.05)$ than those after the capsule (Fig. 2), though the dose of nifedipine administered as granules was double the dose in the capsule. A plasma level of about $13 \mathrm{ng} / \mathrm{ml}$ at $12 \mathrm{~h}$ post-dosing was detected after administration of the granules. If two nifedipine soft gelatin capsules (equal to the dose of the sustained-release granules) are administered to the subjects, high peak plasma levels might produce severe side effects. The slower release of nifedipine from the granules may minimize the side effects, which are a result of high plasma levels. ${ }^{23)}$ Furthermore, it is easy to adjust the dose of the $\mathrm{pH}$-independent release granules to correspond to the severity of the disease, but difficult to do so with a commercial sustained-release tablet ${ }^{5 a-c)}$ or controlled-release capsule which contains rapid release and slow release granules. ${ }^{5 d}$ )

In conclusion, a higher plasma level was detected over the $2-12 \mathrm{~h}$ period, and no great inter-subject variability was noted after oral administration of the nifedipine sustained-release granules prepared in the present study. Twice-daily dosing should be sufficient for therapeutic effectiveness. Thus, this formulation is expected to improve the compliance of patients. 
Acknowledgments The authors are grateful to Kanebo, Ltd., for the generous gift of crystalline nifedipine.

\section{References}

1) a) A. Wilson, J. Pharm. Pharmacol., 11, 44T (1959); b) L. Shargel and A. B. C. Yu (eds.), "Applied Biopharmaceutics and Pharmacokinetics," Appleton-Century-Crofts, Norwalk, Connecticut, 1985, pp. 25-35.

2) a) E. Nelson, J. Am. Pharm. Assoc., Sci. Ed., 46, 572 (1957); b) M. Rowland and A. H. Beckett, J. Pharm. Pharmacol., 16, Suppl., 156T (1964).

3) I. Sugimoto, A. Kuchiki, H. Nakagawa, K. Togoh, S. Kondo, I. Iwane and K. Takahashi, Drug. Dev. Ind. Pharm., 6, 137 (1980).

4) a) I. Sugimoto, A. Kuchiki and H. Nakagawa, Chem. Pharm. Bull., 29, 1715 (1981); b) T. S. Foster, S. R. Hamann, V. R. Richards, P. J. Bryant, D. A. Graves and R. G. McAllister, J. Clin. Pharmacol., 23, 161 (1983).

5) a) A. M. Taburet, E. Singlas, J.-N. Colin, O. Banzet, M. Thibonnier and P. Corvol, Hypertension, 5 (suppl. II), II-29 (1983); b) C. H. Kleinbloesem, P. van Brummelen, J. A. van de Linde, P. J. Voogd and D. D. Breimer, Clin. Pharmacol. Ther., 35, 742 (1984); c) D. Lutz, G. Pabst, W. Dahmen, K.-H. Molz and H. Jaeger, Arzneim.Forsch., 35(II), 1840 (1985); d) A. Hasegawa, H. Nakagawa and I. Sugimoto, Chem. Pharm. Bull., 33, 1615 (1985).

6) N. Kohri, K. Mori, K. Miyazaki and T. Arita, J. Pharm. Sci., 75, 57 (1986).

7) a) P. Jacobsen, O. Lederballe Pedersen and E. Mikkelsen, J. Chromatogr., 162, 81 (1979); b) I. Sugimoto, K. Tohgo, K. Sasaki, H. Nakagawa, Y. Matsuda and R. Masahara, Yakugaku Zasshi, 101, 1149 (1981).

8) "Japanese Pharmacopeia," 10th rev., Hirokawa Publishing, Tokyo, 1981, B-328-339.

9) K. Miyazaki, N. Kohri and T. Arita, J. Chromatogr., 310, 219 (1984).

10) N. B. Shah and B. B. Sheth, J. Pharm. Sci., 61, 412 (1972).

11) S. Borodkin and F. E. Tucker, J. Pharm. Sci., 63, 1359 (1974).

12) J. G. Wagner, J. Pharm. Sci., 58, 1253 (1969).

13) T. Higuchi, J. Pharm. Sci., 52, 1145 (1963).

14) H. Oya Alpar and V. Walters, J. Pharm. Pharmacol., 33, 419 (1981).

15) H. Weintraub and M. Gibaldi, J. Pharm. Sci., 58, 1368 (1969).

16) H. Schott, L. C. Kwan and S. Feldman, J. Pharm. Sci., 71, 1038 (1982).

17) S. Baggesen and H. Bechgaard, Pharm. Acta Helv., 55, 312 (1980).

18) K. D. Raemsch and J. Sommer, Hypertension, 5 (suppl. II), II-18 (1983).

19) H. Bechgaard and G. H. Nielsen, Drug Dev. Ind. Pharm., 4, 53 (1978).

20) a) T. M. Feinblatt and E. A. Ferguson, N. Engl. J. Med., 254, 940 (1956); b) M. Galeone, L. Nizzola, D. Cacioli and G. Moise, Curr. Ther. Res., 29, 217 (1981).

21) a) K. Aoki, K. Sato, Y. Kawaguchi and M. Yamamoto, Eur. J. Clin. Pharmacol., 23, 197 (1982); b) O. Banzet, J. N. Colin, M. Thibonnier, E. Singlas, J. M. Alexandre and P. Corvol, ibid., 24, 145 (1983).

22) K. Kikuchi, H. Kobayashi, T. Nakao, A. Kondo, T. Mito, M. Tsuzuki, O. Iimura, Y. Fujise and K. Hanawa, Jpn. J. Clin. Pharmacol. Ther., 13, 623 (1982).

23) E. Zylber-Katz, G. Koren, L. Granit and M. Levy, Biopharm. Drug Dispos., 5, 109 (1984). 